\title{
Mechanical stretch-induced vascular hypertrophy occurs through modulation of leptin synthesis-mediated ROS formation and GATA-4 nuclear translocation
}

\author{
Crystal M. Ghantous ${ }^{1}$, Firas H. Kobeissy ${ }^{2}$, Nadia Soudani ${ }^{1}$, Farah A. Rahman ${ }^{1}$, \\ Mustafa Al-Hariri ${ }^{2}$, Hana A. Itani ${ }^{3}$, Ramzi Sabra ${ }^{4}$ and Asad Zeidan ${ }^{1 *}$

\begin{abstract}
' Cardiovascular Physiology Lab, Department of Anatomy, Cell Biology and Physiology, American University of Beirut, Beirut, Lebanon, ${ }^{2}$ Department of Biochemistry and Molecular Genetics, American University of Beirut, Beirut, Lebanon, ${ }^{3}$ Division of Clinical Pharmacology, Department of Medicine, Vanderbilt University School of Medicine, Nashville, TN, USA, ${ }^{4}$ Department of Pharmacology and Toxicology, American University of Beirut, Beirut, Lebanon
\end{abstract}

\section{OPEN ACCESS}

Edited by:

Concepción Peiró,

Universidad Autonoma de Madrid,

Spain

Reviewed by:

Siu-Lung Chan,

The University of Vermont, USA

Sean P. Didion,

University of Mississippi Medical

Center, USA

*Correspondence:

Asad Zeidan

asad.zeidan@aub.edu.lb

Specialty section:

This article was submitted to Cardiovascular and Smooth Muscle

Pharmacology,

a section of the journal

Frontiers in Pharmacology

Received: 14 August 2015

Accepted: 05 October 2015

Published: 23 October 2015

Citation:

Ghantous CM, Kobeissy FH, Soudani N, Rahman FA, Al-Hariri M, Itani HA,

Sabra $R$ and Zeidan A (2015)

Mechanical stretch-induced vascular

hypertrophy occurs through

modulation of leptin

synthesis-mediated ROS formation

and GATA-4 nuclear translocation.

Front. Pharmacol. 6:240.

doi: 10.3389/fphar.2015.00240
Background: Obesity and hypertension are associated with increased leptin production contributing to cardiovascular remodeling. Mechanisms involving mechanical stretchinduced leptin production and the cross talk between signaling pathways leading to vascular remodeling have not been fully elucidated.

Methods and Results: Rat portal vein (RPV) organ culture was used to investigate the effect of mechanical stretch on leptin protein expression in vascular smooth muscle cells (VSMCs). Moreover, the involvement of reactive oxygen species (ROS), the RhoA/ROCK pathway, actin cytoskeleton dynamics and the transcriptional factor GATA-4 activation in mechanical stretch-induced vascular remodeling were investigated. Stretching the RPV for 1 or $24 \mathrm{~h}$ significantly increased leptin protein level and ROS formation in VSMCs, which was prevented by $1 \mathrm{~h}$ pretreatment with the ROCK inhibitor Y-27632 and the actin cytoskeleton depolymerization agent cytochalasin D. Moreover, Western blotting and immunohistochemistry revealed that mechanical stretch or treatment with $3.1 \mathrm{nmol} / \mathrm{L}$ leptin for $24 \mathrm{~h}$ significantly increased actin polymerization, as reflected by an increase in the F-actin to G-actin ratio. Increases in blood vessels' wet weight and $\left[{ }^{3} \mathrm{H}\right]$-leucine incorporation following a $24 \mathrm{~h}$ treatment with conditioned media from cultured stretched RPVs indicated RPV hypertrophy. This effect was prevented by $1 \mathrm{~h}$ pretreatment with anti-leptin antibody, indicating leptin's crucial role in promoting VSMC hypertrophy. As an index of GATA-4 activation, GATA-4 nuclear translocation was assessed by immunohistochemistry method. Pretreating VSMC with leptin for $1 \mathrm{~h}$ significantly activated GATA-4 nuclear translocation, which was potently attenuated by the NADPH oxidase inhibitor apocynin, Y-27632, and cytochalasin D.

Conclusion: Our results demonstrate that ROS formation, RhoA/ROCK pathway, and GATA-4 activation play a pivotal role in mechanical stretch-induced leptin synthesis leading to VSMC remodeling.

Keywords: mechanical stretch, leptin, vascular smooth muscle, remodeling, ROS 


\section{INTRODUCTION}

The cardiovascular system is constantly exposed to mechanical stress due to blood pressure. An increase in blood pressure (hypertension) leads to vascular and cardiac remodeling (Zeidan et al., 2003b, 2007; Zhang et al., 2005; Kai et al., 2009). Hypertension, regardless of its underlying cause, is a major risk factor for other cardiovascular diseases, such as vascular hypertrophy, left ventricular hypertrophy, and heart failure (Zeidan et al., 2003b; Zhang et al., 2005). Different signaling pathways are involved in hypertension-induced vascular remodeling (Zeidan et al., 2003b; Zhang et al., 2005) such as the RhoA/ROCK pathway which results in an increased in actin polymerization and depletion in G-actin (Zeidan et al., 2007). Under normal physiological conditions, the ratio of F-actin to G-actin is low, thus attenuating the activity of the transcription factor SRF and down-regulating hypertrophic gene expression (Nelson et al., 2005; Zeidan et al., 2006). However, activation of the RhoA/ROCK pathway increases F-actin to G-actin ratio and as a result, promotes vascular remodeling and hypertrophy. PI3K/AKT pathway is another pathway that is involved in the changes in actin cytoskeleton dynamics via LIMK/cofilin phosphorylation (Zeidan et al., 2007). Thus there is a cross-talk between the PI3K/AKT and RhoA/ROCK pathways in promoting vascular hypertrophy (Li et al., 2009; Fan et al., 2014). The activation of the MAP kinases ERK1/2 and p38 is also another essential pathway involved in mechanical stretch-induced VSMC hypertrophy (Zeidan et al., 2000).

Hypertension is associated with high levels of the obesityassociated protein leptin (hyperleptinemia; Agata et al., 1997; Uckaya et al., 1999). In addition, we have previously shown that mechanical stretch, which mimics hypertension, enhances the release of leptin from vascular smooth muscle cells (VSMCs; Zeidan et al., 2005). Leptin is a $16 \mathrm{kDa}$ protein that is best known for its function as a satiety factor. It circulates in the blood of lean individuals at levels between 5 and $15 \mathrm{ng} / \mathrm{mL}$ (Sinha et al., 1996). These levels are higher in obese individuals and may reach up to $50 \mathrm{ng} / \mathrm{mL}$, due to a higher adipose tissue mass (Sinha et al., 1996). In addition to adipocytes, leptin is produced by other kinds of cells including cardiomyocytes and VSMCs (Zeidan et al., 2005; Matsui et al., 2007). Different studies have shown that the functional leptin receptor, leptin receptor $b(\mathrm{OBRb})$, is found in a variety of cells such as VSMCs (Zeidan et al., 2005; Zeidan and Karmazyn, 2006), cardiomyocytes (Rajapurohitam et al., 2003), myometrial cells (Markowska et al., 2005), endothelial cells (Mutze et al., 2006), and T-lymphocytic cells (Martin-Romero et al., 2000; Lord et al., 2002). Therefore, this hormone has a wide range of pleiotropic effects and affects the cardiovascular, nervous, reproductive, and immune systems (Lord et al., 1998; Margetic et al., 2002; Rahmouni and Haynes, 2004). Leptin promotes hypertension, vascular remodeling, sympathetic nervous system stimulation, ROS generation, angiogenesis, and atherosclerosis (reviewed, by Ghantous et al., 2015). Hence, leptin potentially contributes to many cardiovascular risks associated with obesity.

Blood vessels exposed to hypertension generate excessive levels of reactive oxygen species (ROS; Paravicini and Touyz,
2006, 2008; Montezano and Touyz, 2012). The main source of cardiovascular ROS is a family of NADPH oxidases (Nox), such as Nox1, Nox2, Nox4, and Nox5 (Montezano and Touyz, 2012). Under stressful environmental conditions like hypertension, ROS levels increase in a phenomenon known as oxidative stress (Montezano and Touyz, 2012). ROS-mediated endothelial cell and VSMC damage promotes remodeling of the vasculature and atherosclerosis (Touyz and Schiffrin, 2004; Mei et al., 2015).

The transcription factor GATA-4 has been studied in the cardiac system to promote hypertrophy by translocating to the nucleus and activating hypertrophic gene expression, such as $\beta$-MHC, c-fos, c-jun, c-myc, BNP, and ANF (Chien et al., 1991; Liang and Gardner, 1999; Saadane et al., 1999; Babu et al., 2000; Hsieh et al., 2015). For example, GATA-4 has been shown to modulate the transcriptional activation of angiotensin II type ${ }_{1 A}$ receptor and $\beta$-MHC in pressure overload-induced cardiac hypertrophy (Herzig et al., 1997; Oka et al., 2006). GATA-4 also interacts with NFAT3, another transcription factor that is involved in promoting cardiac hypertrophy (Molkentin et al., 1998). Thus, GATA-4 has been well characterized in the cardiac system in promoting hypertrophy; however, the present knowledge of the role it plays in the vascular system has been limited to regulating cardiac angiogenesis (Heineke et al., 2007) and embryonic angiogenesis in the vascular plexus (Torregroza et al., 2012). Since GATA-4 is well known to promote cardiac hypertrophy, it is interesting to study whether leptininduced vascular remodeling could be mediated by GATA4, thus discovering a new role for GATA-4 in the vascular system.

The mechanisms by which hypertension/leptin or ROS induce vascular hypertrophy have not been fully elucidated yet. Accordingly, the present study was designed to determine the interaction between hypertension, leptin, and ROS and to identify their role in promoting vascular hypertrophy. In addition, the involvement of the RhoA/ROCK pathway and actin cytoskeleton remodeling in hypertension/leptininduced ROS formation and vascular hypertrophy were investigated in this study. The transcriptional factor GATA4 nuclear translocation was also examined in order to take a detailed look at the mechanism promoting VSMC hypertrophy.

To achieve these aims, rat portal vein (RPV) organ culture was used. This blood vessel is a large vessel that is both preand post-capillary and has spontaneous myogenic tone (Sutter, 1990; Zeidan et al., 2000). Being a low-pressure vessel, it is very sensitive to pressure increase (Malmqvist and Arner, 1988, 1990). Moreover, the RPV has been extensively used as an analog of small pre-capillary resistance vessels (Ljung, 1990; Sutter, 1990). Morphologically, the portal vein has a thin inner circular layer of VSMCs and a thick, very pronounced longitudinal layer of VSMCs (Sutter, 1990). The longitudinal orientation of the VSMCs provides an in vitro model to mimic hypertension by mechanically stretching it using weights that stretch the vein equivalently to the in vivo force of stretch exerted on blood vessels in hypertension (see Rat Portal Vein Organ Culture). 


\section{MATERIALS AND METHODS}

\section{Rat Portal Vein Organ Culture}

Male Sprague-Dawley rats (200-250 g) were killed by $\mathrm{CO}_{2}$, as approved by the Animal Ethics Committee, American University of Beirut. The investigation conforms to the Guide for the Care and Use of Laboratory Animals published by the US National Institutes of Health (NIH Publication No. 85-23, revised 2011). RPVs were dissected in a sterile environment and cleaned in $\mathrm{N}$-Hepes buffer solution $(400 \mathrm{mM} \mathrm{NaCl}, 200 \mathrm{mM} \mathrm{KCl}, 100 \mathrm{mM}$ $\mathrm{MgCl}$, $100 \mathrm{mM}$ Hepes, $11.5 \mathrm{mM}$ Glucose, 5\% penicillinstreptomycin). RPVs were cut longitudinally resulting in two equal portal vein strips and weighed when needed. Silver weights of $0.6 \mathrm{~g}$ (stretch the blood RPV slightly above optimal length or $10 \%$ stretch) were tied to the end of the strip on which stretch studies were to be performed. The other strip was left unstretched and used as a control. In cases where an entire vein was needed, weights of $1.2 \mathrm{~g}$ were used. The strips were then transferred to culture media of DMEM/F-12 HAM with 5\% penicillin/ streptomycin). RPVs were incubated at $37^{\circ} \mathrm{C}$ and $5 \% \mathrm{CO}_{2}$ in air. When leptin (Rat Leptin, Biovision, San Francisco, USA) was used as treatment, a concentration of $3.1 \mathrm{nmol} / \mathrm{L}$ was added.

Inhibitors such as the selective ROCK inhibitor Y27632 (10 $\mu \mathrm{mol} / \mathrm{L}$, Sigma Aldrich, MO, USA), the actin depolymerization agent cytochalasin D $(1 \mu \mathrm{mol} / \mathrm{L}$; Calbiochem, CA, USA), the NADPH oxidase inhibitor apocynin $(1 \mu \mathrm{mol} / \mathrm{L}$, 4-Hydroxy-3-methoxyacetophenone, Sigma Aldrich, MO, USA), and the anti-leptin antibody Ob (Y-20) $(1 \mu \mathrm{mol} / \mathrm{L}$; Santa Cruz Biotechnology, CA, USA) were added to the media $60 \mathrm{~min}$ before mechanically stretching the RPV or adding leptin. Following incubation, the RPV strips were taken out of the incubator and either weighed (Zeidan et al., 2000) or immediately frozen in liquid nitrogen and stored at $-80^{\circ} \mathrm{C}$ for protein analysis.

When conditioned media (CM) was used, RPVs were cultured in DMEM F-12 HAM either unstretched or stretched for $24 \mathrm{~h}$. Media was then centrifuged at $800 \times g$ for $10 \mathrm{~min}$, followed by centrifugation at 5000 RPM for 15 min with a Centricon Plus-20 filter (Millipore Corporation, MA, USA) to concentrate the media 100 -fold and yield concentrated CM.

\section{Immunoblotting}

Rat portal veins were homogenized in $100 \mu \mathrm{L}$ of lysis buffer (50 mM Tris, $\mathrm{pH} 8.0,150 \mathrm{mM} \mathrm{NaCl}, 1 \%$ Nonidet-P40, $0.5 \%$ sodium deoxycholate) using liquid nitrogen. Proteins were extracted after centrifugation for $10 \mathrm{~min}$ at $4^{\circ} \mathrm{C}$ and quantified using Bradford assay. Protein expression and phosphorylation were determined by Western blot as previously described (Zeidan et al., 2006). Primary antibodies for leptin [anti-leptin antibody Ob (Y-20), Santa Cruz Biotechnology, CA, USA], p-GATA-4 (Ser 262, Santa Cruz Biotechnology, CA, USA), and GAPDH (Santa Cruz Biotechnology, CA, USA) were added to the membranes at 1:1000 ratio with $3 \%$ BSA for $1 \mathrm{~h}$.

\section{Measurement of G-actin/F-actin Ratio}

F-actin and G-actin were extracted and blotted as described previously (Zeidan et al., 2007). Briefly, RPVs were snap-frozen and homogenized in F-actin stabilization buffer $[50 \mathrm{mmol} / \mathrm{L}$
PIPES, $5 \mathrm{mmol} / \mathrm{L} \mathrm{MgCl} 2,50 \mathrm{mmol} / \mathrm{L} \mathrm{NaCl}, 5 \mathrm{mmol} / \mathrm{L}$ EGTA, 5\% (v/v) lyceral, $0.1 \%(\mathrm{v} / \mathrm{v})$ Triton X-100, 0.1\% (v/v) Nonidet P-40, $0.1 \%(\mathrm{v} / \mathrm{v})$ Tween $20,0.1 \%(\mathrm{v} / \mathrm{v}) 2$-mercaptoethanol and $0.001 \%$ $(\mathrm{v} / \mathrm{v})$ antifoam and a protease inhibitor cocktail] followed by high speed centrifugation for $1 \mathrm{~h}$ at $100,000 \times g$ to separate the $\mathrm{G}$-actin (supernatants) from F-actin (pellets). In order to depolymerize the F-actin, the pellets were resuspended in cold cytochalasin D ( $1 \mu \mathrm{mol} / \mathrm{L}$; Calbiochem, CA, USA). Equal amounts of both the supernatant and the resuspended pellet were subjected to Western blot analysis using rabbit polyclonal actin antibody (Cell Signaling Technology, MA, USA).

\section{Measurement of Protein Synthesis}

Rat portal veins were kept in organ culture with the different kinds of CM for 2 days. RPVs were then cultured for another $24 \mathrm{~h}$ with $\left[{ }^{3} \mathrm{H}\right]$-leucine in order to measure protein synthesis as described previously (Zeidan et al., 2003b).

\section{RNA Isolation and Real-time PCR}

RNA was isolated and Real-Time PCR was done as previously described (Zeidan et al., 2005). The primers were: Nox1 forward $5^{\prime}$-TTTCCTAAACTACCGACTC- $3^{\prime}$ and Nox1 reverse $5^{\prime}$-GTGCGACAACGGACTATC- $3^{\prime}$, Nox2 forward $5^{\prime}$-CCCTTTGGTACAGCCAGTGAAGAT- $3^{\prime}$ and Nox 2 reverse $5^{\prime}$-CAATCCCAGCTCCCACTAACATCA-3', Nox4 forward $5^{\prime}$-GGATCACAGAAGGTCCCTAGCAG- $3^{\prime}$ and Nox4 reverse $5^{\prime}$-GCAGCTACATGCACACCTGAGAA- $3^{\prime}$, and $18 \mathrm{~S}$ rRNA forward $5^{\prime}$-GTAACCCGTTGAACCCCATT- $3^{\prime}$ 18S rRNA reverse $5^{\prime}$-CCATCCAATCGGTAGTAGCG- ${ }^{\prime}{ }^{\prime}$ which was used as the housekeeping gene to normalize expression.

\section{ROS Analysis}

Reactive oxygen species production in response to mechanical stretch or leptin was detected by dihydroethidium (DHE) staining (10 $\mu \mathrm{M}$, Sigma-Aldrich). RPV slices (5 $\mu \mathrm{m}$-thick frozen sections) were incubated with $\mathrm{DHE}$ at $37^{\circ} \mathrm{C}, 5 \% \mathrm{CO}_{2}$ for $30 \mathrm{~min}$ in a humidified chamber protected from light. Positive DHE intensity signals were quantified using a laser confocal microscope (LSM710, ZEN confocal software Carl Zeiss).

\section{Immunohistochemistry}

To visualize leptin expression, $5 \mu$ m-thick frozen RPV sections were fixed using $4 \%$ formaldehyde and permeabilized using $0.2 \%$ Triton X-100. Nonspecific binding was blocked by $1 \%$ BSA, $0.1 \%$ Triton $\mathrm{x}-100$ in PBS for $10 \mathrm{~min}$ followed by incubation with anti-leptin antibody $[\mathrm{Ob}(\mathrm{Y}-20)$ at $1: 100$ ratio in $1 \%$ BSA and $0.05 \%$ Tween in PBS] for $1 \mathrm{~h}$. RPV sections were then washed and incubated for another hour at room temperature with Alexa 594-conjugated goat anti-mouse secondary antibody (1:250 in $1 \%$ BSA and $0.05 \%$ Tween in PBS; Molecular Probes). Images were acquired with a laser confocal microscope (LSM710, ZEN confocal software Carl Zeiss).

For F-actin and G-actin ratio study, RPV frozen sections were fixed in $4 \%$ formaldehyde, $0.2 \%$ Triton $\mathrm{x}-100$ in the cytoskeleton stabilizing PEM buffer (100 mM PIPES, $5 \mathrm{mM}$ EGTA, $2 \mathrm{mM}$ $\mathrm{MgCl} 2, \mathrm{pH}$ 6.9) for $20 \mathrm{~min}$ at room temperature. Thereafter, the 
sections were permeabilized, blocked, and stained with the F-actin stain Phalloidin (100 nM; Acti-stain 555 phalloidin, Cytoskeleton, Denver, CO, USA) and the G-actin stain Deoxyribonuclease I (300 nM; Alexa Fluor 488 conjugate, Invitrogen, NY, USA). All sections were examined and positive intensity signals were quantified using a laser confocal microscope (LSM710, ZEN confocal software Carl Zeiss).

\section{Detection of GATA-4 Nuclear Translocation}

Rat Aortic Smooth Muscle Cells (RASMC) were cultured at a concentration of $40 \times 10^{3}$ per $\mathrm{ml}$ in DMEM media supplemented with $10 \%$ fetal bovine serum for $72 \mathrm{~h}$ and then starved for another $24 \mathrm{~h}$. Leptin $(3.1 \mathrm{nmol} / \mathrm{L})$ was added with or without Y-27632 $(10 \mu \mathrm{mol} / \mathrm{L})$, cytochalasin D $(1 \mu \mathrm{mol} / \mathrm{L})$, or apocynin $(1 \mu \mathrm{mol} / \mathrm{L})$. Cells were then rinsed twice with PBS without $\mathrm{Ca}^{2+} / \mathrm{Mg}^{2+}$, fixed with $4 \%$ paraformaldehyde for $10 \mathrm{~min}$, permeabilized with $0.2 \%$ Triton X-100 for $20 \mathrm{~min}$, and blocked with $1 \%$ BSA, $0.1 \%$ Triton $\mathrm{x}-100$ in PBS for $1 \mathrm{~h}$. Anti-GATA-4 antibody (GATA-4, Santa Cruz Biotechnology, CA, USA) at 1:100 ratio in 1\% BSA, $0.05 \%$ Tween in PBS was incubated with the RASMC overnight at $4^{\circ} \mathrm{C}$, followed by incubation with CruzFluor 488 -conjugated goat anti-mouse secondary antibody (1:250 in 1\% BSA and $0.05 \%$ Tween in PBS) in the dark for $1 \mathrm{~h}$. Phalloidin (100 nM; Actistain 555 phalloidin, Cytoskeleton, Denver, CO, USA) was then added for $20 \mathrm{~min}$ to stain actin. Images were acquired using a laser confocal microscope (LSM710, ZEN confocal software Carl Zeiss).

\section{Determination of Leptin Release}

To determine whether mechanical stretch stimulates leptin release from VSMCs, culture medium was assayed for leptin protein by using a TiterZyme enzyme immunometric assay kit (Assay Designs, Inc., Ann Arbor, MI, USA).

\section{Statistical Analysis}

Values for the experimental groups were normalized to the unstretched RPVs. Data values are presented as mean \pm standard error of the mean (SEM). Statistical data was analyzed using $t$ test or one-way analysis of variance (ANOVA), and significance was established by Holm-Sidak or Tukey methods. Statistical significance was considered for $p<0.05$ between groups.

\section{RESULTS}

\section{Mechanical Stretch/hypertension Increases the Intracellular Leptin Protein Levels in VSMCs}

We have shown previously the ability of mechanical stretch to induce leptin secretion into culture media after 1-3 days of stretching (Zeidan et al., 2005). In this study, we investigated the effect of mechanical stretch on the endogenous leptin expression level in VSMCs. RPVs were cultured for $1 \mathrm{~h}$ or $24 \mathrm{~h}$ with or without stretch.

The effect of mechanical stretch on leptin expression in VSMCs was first analyzed using a laser confocal microscope (LSM710, ZEN confocal software, Carl Zeiss). Figures 1A,B show that intracellular leptin levels were significantly increased after 1 and $24 \mathrm{~h}$ of mechanical stretch. These findings indicate that mechanical stretch has the ability to induce leptin protein synthesis at early $(1 \mathrm{~h})$ and late stages $(24 \mathrm{~h})$. In agreement with the previous study of immunohistochemistry, Western blot analysis of protein lysates prepared from the RPVs revealed that intracellular leptin expression was significantly increased after $1 \mathrm{~h}$ of mechanical stretch by fourfold and after $24 \mathrm{~h}$ of stretch by 2.5 fold (Figure 1C).

To explore the role of mechanical stretch-induced leptin expression on leptin release from VSMCs into the culture medium, we examined the effect of mechanical stretch for 1 , $3,6,18$, and $24 \mathrm{~h}$ on leptin release using an immunometric assay. Figure 1D shows that stretching RPVs for 3, 6, 18, or $24 \mathrm{~h}$ significantly induced leptin release into the culture medium. These results indicate the direct effect of mechanical stretch on both leptin synthesis and release.

\section{Role of Endogenous Leptin in Mediating Stretch-induced Hypertrophy}

We tested the hypertrophic effect of CM taken from RPVs unstretched or stretched for $24 \mathrm{~h}$. The $\mathrm{CM}$ removed from unstretched RPVs [CM (Unst $24 \mathrm{~h}$ )] had no effect on wet weight or protein synthesis of RPVs cultured for 3 days with the CM (Figures 2A,B). However, CM taken from stretched RPVs [CM (St 24 h)] significantly increased RPV wet weight (Figure 2A) as well as protein synthesis (Figure 2B). We also determined the relationship between wet and dry RPV weights in control and hypertrophied strips (data not shown); there were no significant differences in the dry weight/wet weight ratios in different groups, indicating that increased tissue weights were not due to increased water retention.

To ascertain whether CM-induced hypertrophy was mediated by leptin, RPVs were cultured for 3 days with anti-leptin antibody ( $1 \mu \mathrm{mol} / \mathrm{L}$ ) and CM taken from stretched RPVs for $24 \mathrm{~h}$ [CM (St $24 \mathrm{~h})+$ Anti-Lep]. As shown in Figures 2A,B, treatment with anti-leptin antibody significantly attenuated CM-induced increase in tissue weight and protein synthesis, suggesting that the hypertrophic effect of CM is mediated, at least in part, by leptin in CM.

\section{Mechanical Stretch- and Leptin-induced Actin Cytoskeleton Remodeling}

Since hypertrophy is characterized by remodeling of the actin cytoskeleton, Western blot analysis was performed for G-actin and F-actin in order to study the effect of mechanical stretch on hypertrophy. RPVs were mechanically stretched for $24 \mathrm{~h}$, and the ratio of F-actin to G-actin was calculated and normalized to the unstretched (control) RPVs (Figure 3A). The F/G-actin ratio for the stretched RPVs was significantly greater (approximately 5.6 fold) than that for the control RPVs (Figure 3A), indicating that the levels of F-actin had increased significantly relative to those of G-actin, a main indicator of hypertrophy (Figure 3).

Rat portal veins were treated with leptin at a concentration of $3.1 \mathrm{nmol} / \mathrm{L}(50 \mathrm{ng} / \mathrm{mL})$ due to its equivalence to leptin concentrations in obesity (Maffei et al., 1995; Rajapurohitam 


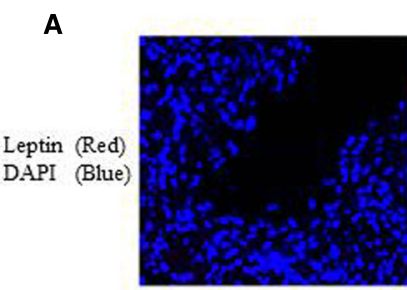

Unst

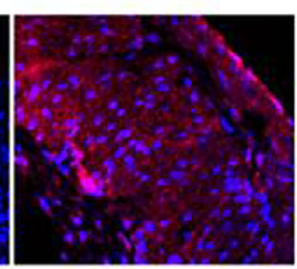

St 1 hr

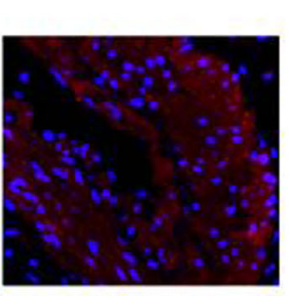

St $24 \mathrm{hr}$

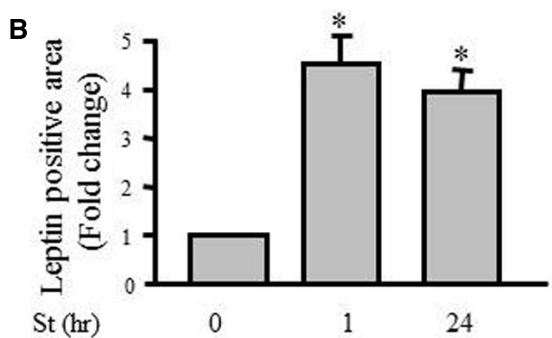

C
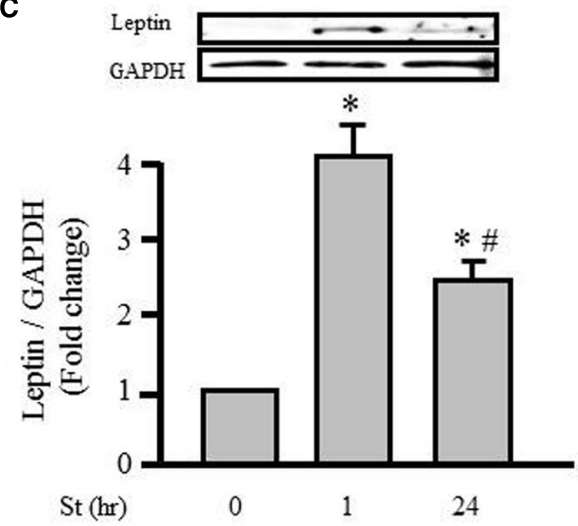

D

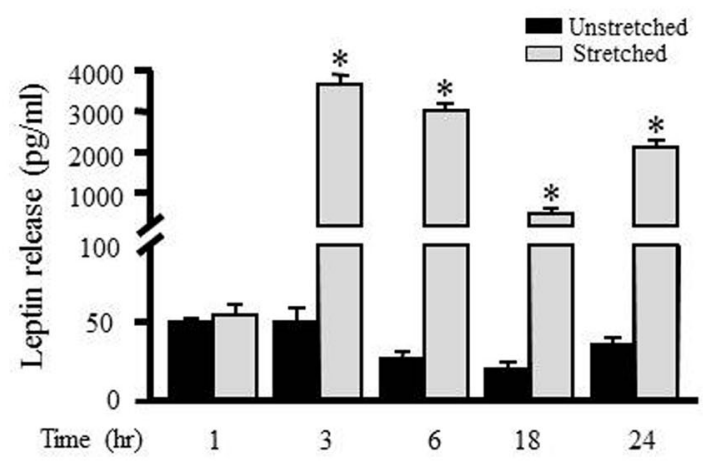

FIGURE 1 | Mechanical stretch-induced intracellular leptin protein expression and secretion. RPVs were subjected to stretch for 1 or 24 h (A). Representative confocal microscopic images for leptin detection in RPV wall after stretching for 1 or $24 \mathrm{~h}$. DAPI stained the nuclei blue, while leptin primary antibody was visualized by Alexa 594-conjugated secondary antibody (red). (B). Fluorescence intensity measurements of leptin protein detected by immunohistochemistry. (C). Expression of leptin protein was evaluated using Western blotting densitometric scans and normalized to the unstretched RPVs. ( $n=5-9$ ). Stretch for $1 \mathrm{~h}$ significantly increased intracellular leptin expression, more than stretch for $24 \mathrm{~h}$. (D). Leptin release into the extracellular media was measured using ELISA for mechanically stretched RPVs for 1, 3, 6, 18, or $24 \mathrm{~h}$. Leptin release significantly increased after $3-24 \mathrm{~h}$ of stretch. ${ }^{*} p<0.05$ versus unstretched (Unst). \#p $<0.05$ versus stretched $1 \mathrm{~h}$ (St $1 \mathrm{~h})$.

A

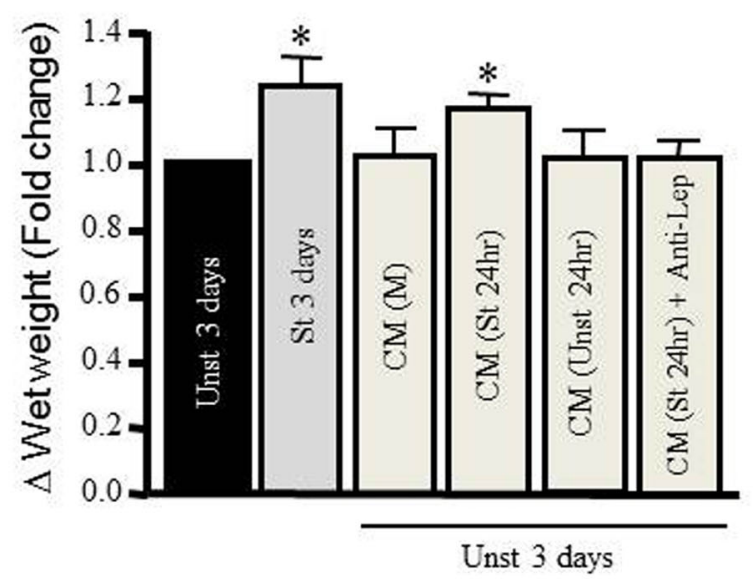

B

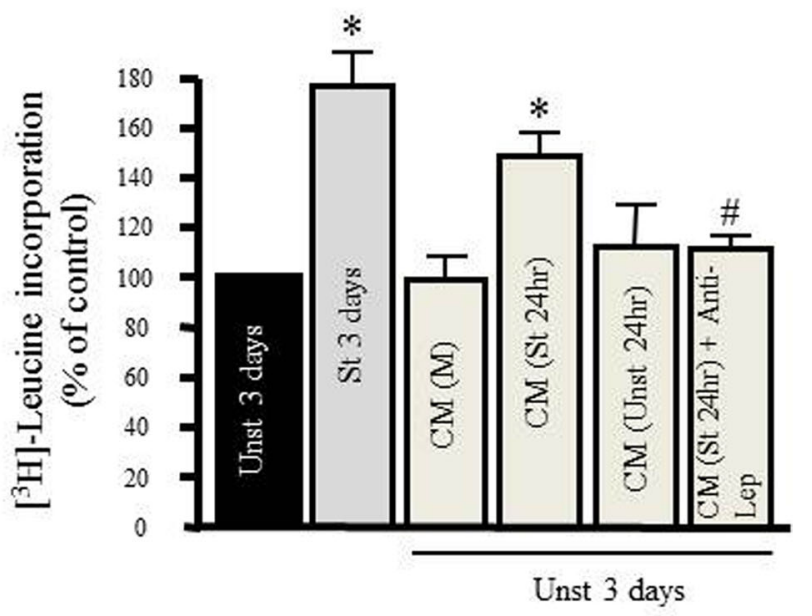

FIGURE 2 | Mechanical stretch-induced VSMC hypertrophy is mediated by leptin protein release. Effect of different kinds of conditioned media (CM) prepared from either media alone (M), from unstretched (Unst) RPVs' media (Unst 24 h), from stretched RPVs' media (St 24 h), or CM from stretched RPVs with anti-leptin antibody [CM(St $24 \mathrm{~h})+$ Anti-Lep] on tissue wet weight (A) and $\left[{ }^{3} \mathrm{H}\right]$-leucine incorporation (B) in RPVs cultured for 3 days. ${ }^{*} p<0.05$ versus unstretched (Unst). ( $n=6-9)$. \#p $<0.05$ versus stretched $24 \mathrm{~h}$ (St $24 \mathrm{~h})$.

et al., 2003; Zeidan et al., 2005) for $24 \mathrm{~h}$ and the ratio of F/Gactin was calculated and normalized to unstretched (untreated) RPVs (Figure 3D). Similarly to the effect of mechanical stretch, treatment with leptin resulted in a significant increase in F/Gactin ratio (approximately 1.5 fold), indicating that leptin alone indeed promotes vascular remodeling in the form of hypertrophy. 
A

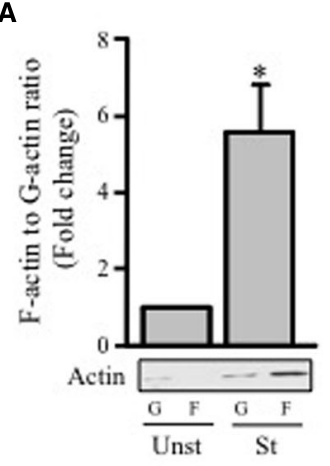

D

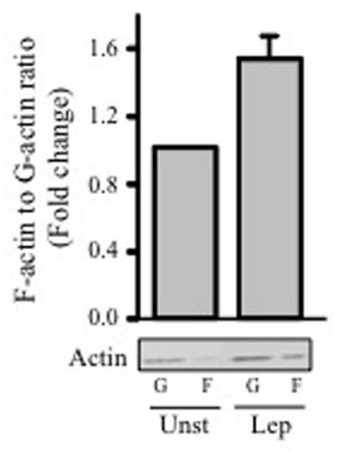

B

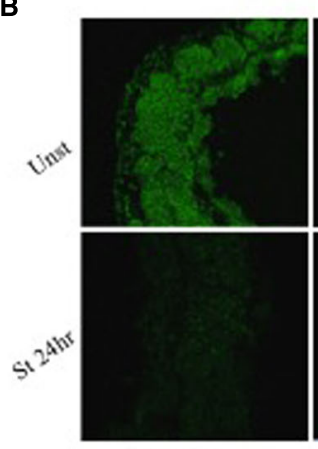

G-actin

E

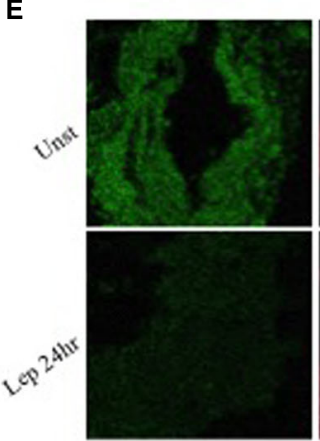

G-actin

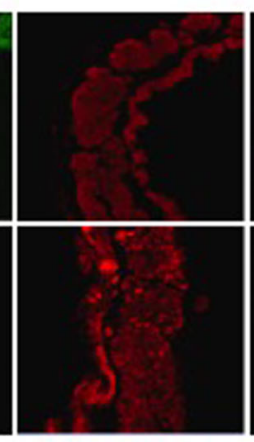

F-actin

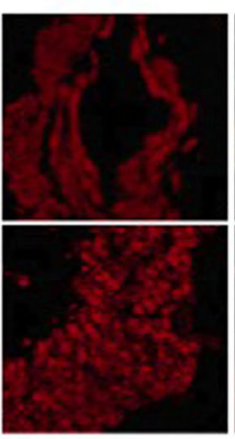

F-actin

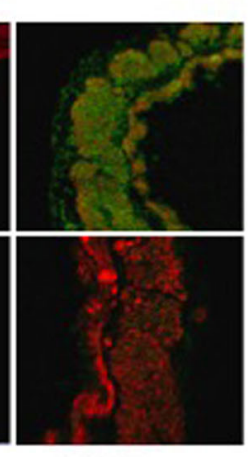

Merged

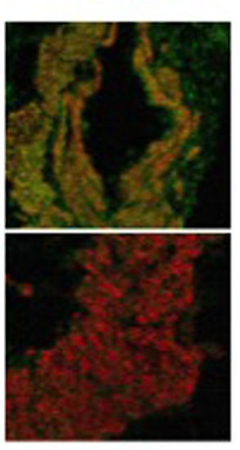

Merged
C

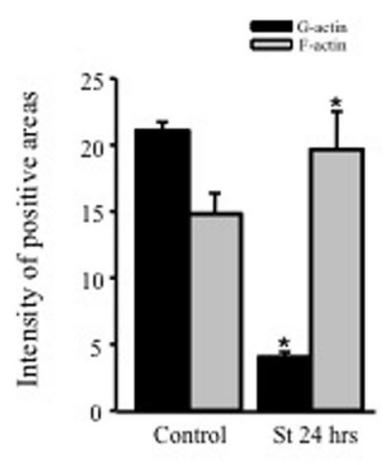

$\mathbf{F}$

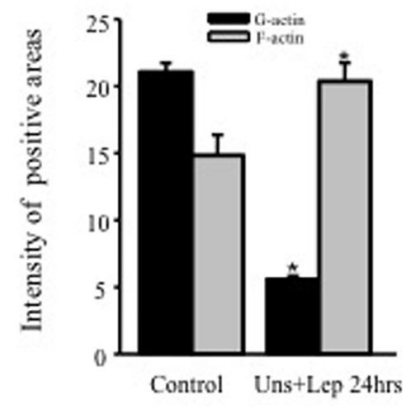

FIGURE 3 | Mechanical stretch- and leptin- induced actin cytoskeleton dynamics. RPVs were cultured for $24 \mathrm{~h}$ under mechanical stretch (A-C) or treated with $3.1 \mathrm{nmol} / \mathrm{L}$ leptin (D-F). F- and G-actin were separated by ultracentrifuge followed by Western blot of pellets (F-actin; F) and supernatants (G-actin; $\mathrm{G})$. ( $n=5)$. ${ }^{*} p<0.05$ versus unstretched (Unst). Representative confocal microscopic images for RPV wall stained with the G-actin stain Deoxyribonuclease I (B,E); (left panels; green) and the F-actin stain Acti-stain 555 phalloidin (B,E); (middle panels; red). The overlay of both F-and G-actin (merged) is shown in the right panels (B,E). $(n=3)$. Quantification of Phalloidin and Deoxyribonuclease I positive areas indicate that mechanical stretch (C) or leptin (F) for $24 \mathrm{~h}$ resulted in a decrease in $\mathrm{G}$-actin levels and increase in F-actin levels.

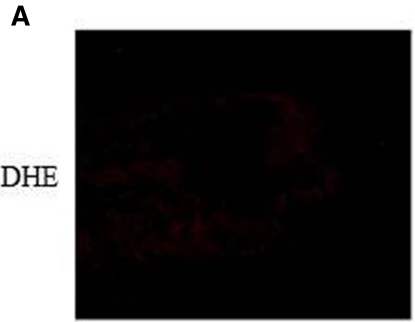

Unst

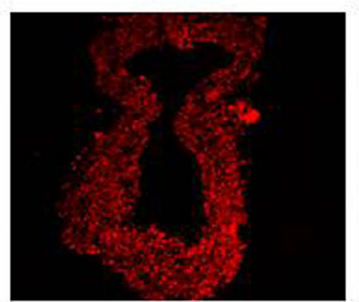

St $1 \mathrm{hr}$

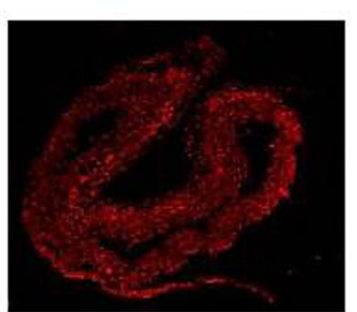

St $24 \mathrm{hr}$

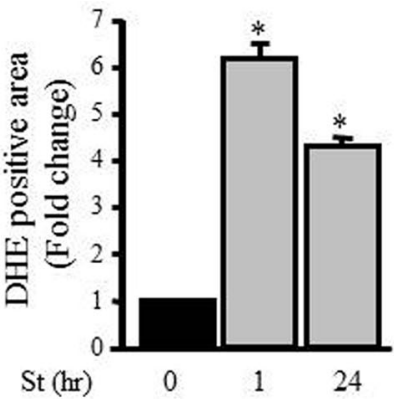

FIGURE 4 | Mechanical stretch-induced ROS production. (A). Representative confocal microscopic images of RPV wall stained with DHE. (B). Fluorescence intensity measurements of DHE positive area of the mechanically stretched RPVs for 1 or $24 \mathrm{~h}(n=4)$. ${ }^{*} p<0.05$ versus unstretched (0 h).

The effect of mechanical stretch and leptin on actin cytoskeleton remodeling of RPVs was also analyzed by confocal microscopy using Phalloidin and Deoxyribonuclease I to stain F-actin and G-actin, respectively. Stretching RPVs or treating with leptin for $24 \mathrm{~h}$ significantly lowered G-actin levels and increased F-actin compared to the controls (Figures 3B,C,E,F), consistent with the Western blot findings.

\section{Mechanical Stretch Induces ROS Production in VSMCs}

Figure 4A shows that the DHE fluorescence level (red fluorescent signal; ROS) in the unstretched RPV (control) was low while the DHE fluorescence intensity significantly increased after 1 and $24 \mathrm{~h}$ of mechanical stretch (six- and fourfolds, respectively) compared to unstretched RPV (Figures 4A,B). 


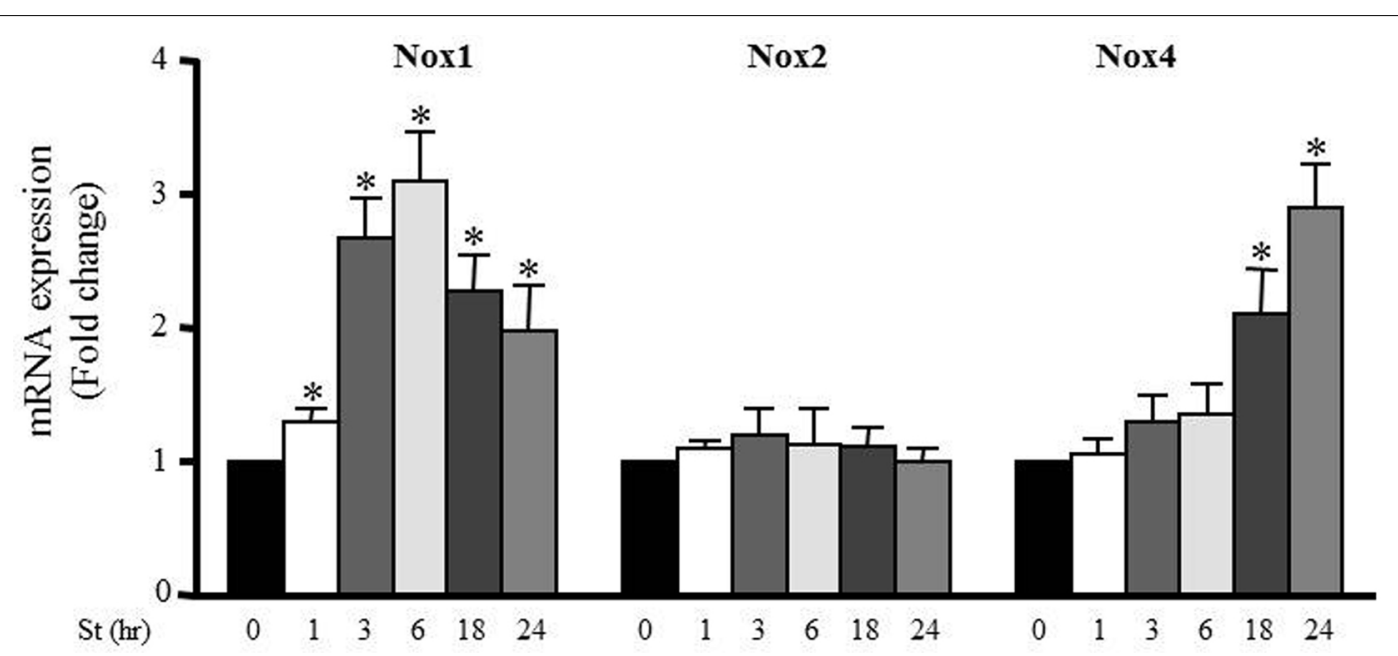

FIGURE 5 | Mechanical stretch-induced Nox expression. Effect of mechanical stretch on the mRNA expression of Nox1, Nox2, and Nox4. $(n=8-10) .{ }^{*} p<0.05$ versus control $(\mathrm{O} \mathrm{h})$

A

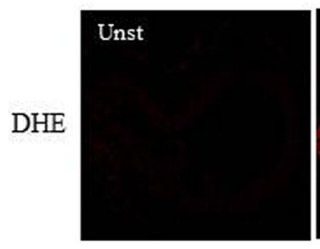

C
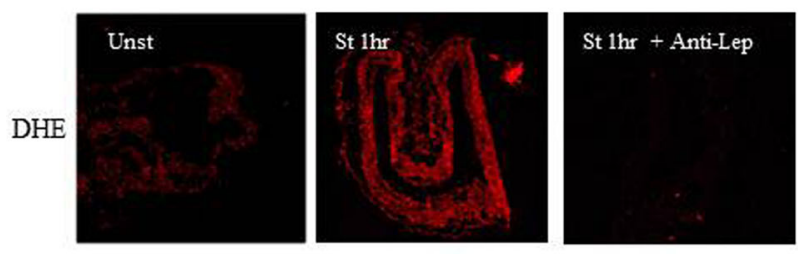

E
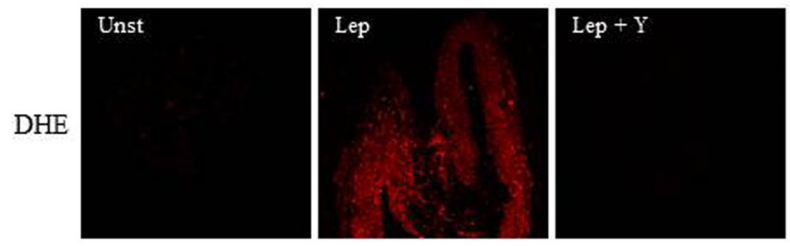

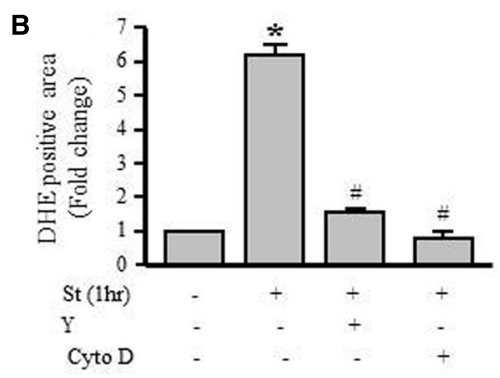

D
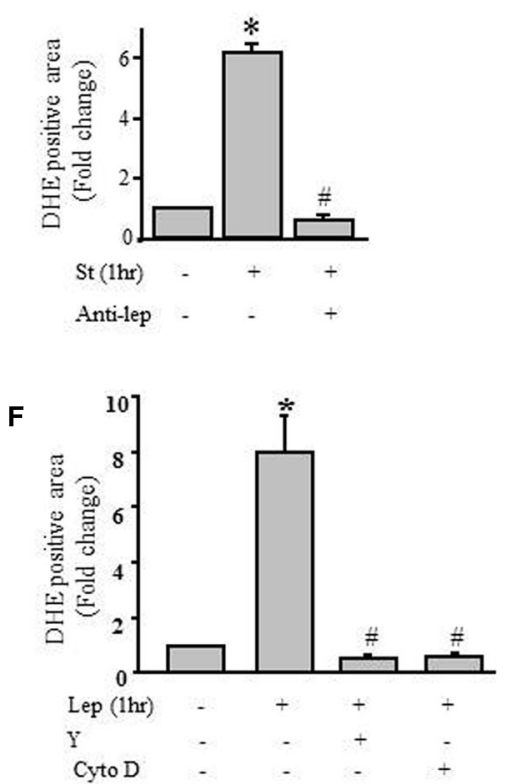

FIGURE 6 | Role of the RhoA/ROCK pathway in leptin- / mechanical stretch-induced ROS formation. Effect of Y-27632 (Y; $10 \mu \mathrm{mol} / \mathrm{L})$ or cytochalasin D (Cyto D; 1 umol/L) on mechanical stretch- (A) and leptin- (E) induced ROS formation. (C). Effect of inhibition of leptin by anti-leptin antibody (Anti-Lep) on mechanical stretch-induced ROS formation. Fluorescence intensity measurements of DHE positive area of the mechanically stretched (B,D) and leptin-induced (F) RPVs treated with Anti-Lep, Y, or Cyto $D(n=3) .{ }^{*} p<0.05$ versus unstretched (Unst). $\# p<0.05$ versus stretched $1 \mathrm{hr}(\mathrm{St} 1 \mathrm{~h}$ ). 
Accumulating evidence suggests that NADPH oxidase (Nox) activity and expression have an important role in ROS formation in various cells types including VSMCs (Clempus and Griendling, 2006; Lyle and Griendling, 2006). To investigate the effect of mechanical stretch on Nox expression, RPVs were stretched for $1,3,6,18$, or $24 \mathrm{~h}$ and the mRNA expressions of Nox1, Nox2, and Nox4 were analyzed using qPCR. Nox1 and Nox4 mRNA expressions were increased after mechanical stretch, while Nox2 mRNA expression was not affected by mechanical stretch (Figure 5). These data indicate that Nox1 and Nox4 may be important in producing ROS after $24 \mathrm{~h}$ of stretch, but perhaps not so much after $1 \mathrm{~h}$. On another hand, Nox 2 expression had no role in mediating mechanical stretch-induced ROS formation.

\section{ROS Formation is Mediated by Leptin and the RhoA Pathway}

To gain insight into the mechanism underlying the mechanical stretch-induced increase in ROS production, stretched RPVs for $1 \mathrm{~h}$ were pretreated with the ROCK inhibitor Y-27632 compound $(10 \mu \mathrm{mol} / \mathrm{L})$ and the actin depolymerization agent cytochalasin $\mathrm{D}$ $(1 \mu \mathrm{mol} / \mathrm{L})$. DHE fluorescence revealed that treatment with either Y-27632 compound or cytochalasin D significantly decreased mechanical stretch-induced ROS formation (Figures 6A,B), suggesting the involvement of the RhoA/ROCK pathway and the importance of an intact cytoskeleton in the production of ROS induced by mechanical stretch.

To investigate whether leptin synthesis is involved in mechanical stretch-induced ROS formation, RPVs were pretreated anti-leptin antibody for $1 \mathrm{~h}$ followed by mechanical stretch for $1 \mathrm{~h}$. Figures 6C,D show that anti-leptin antibody significantly prevented mechanical stretch-induced ROS production, indicating the significant role of leptin in mechanical stretch-induced ROS generation.

To gain more information about the effect of exogenous leptin on ROS formation, RPVs were treated with $3.1 \mathrm{nmol} / \mathrm{L}$ leptin for $1 \mathrm{~h}$, equivalent to leptin concentrations in obesity. Figures $6 \mathrm{E}, \mathrm{F}$ shows that leptin treatment significantly increased ROS formation, whereas pretreatment with Y-27632 or cytochalasin D significantly attenuated leptin-induced ROS production. These data show the involvement of Rho/ROCK pathway and intact actin cytoskeleton in leptin-induced ROS formation.

We also assessed whether Y-27632 and cytochalasin D could prevent the mechanical stretch-induced upregulation of Nox1 and Nox 4 mRNA expression using qPCR analysis after 6 and $24 \mathrm{~h}$, respectively (the peaks of mRNA upregulation). Figure 7 shows that upregulation of Nox 1 and Nox 4 induced by mechanical stretch was attenuated when RPVs were pre-treated with Y-27632 or cytochalasin $\mathrm{D}$, indicating the involvement of ROCK activation and an intact actin cytoskeleton in mechanical stretch-induced Nox1 and Nox4 overexpressions.

\section{Leptin Induces GATA-4 Phosphorylation and Nuclear Translocation}

GATA-4 is a transcription factor that translocates from the cytoplasm to the nucleus upon activation, and in turn upregulates hypertrophic gene expression. To study whether the hypertrophic effect of leptin was mediated by GATA-4 phosphorylation and nuclear translocation, RASMC were treated with leptin $(3.1 \mathrm{nmol} / \mathrm{L})$ for 15,30 , and $60 \mathrm{~min}$, followed by Western blotting or immunostaining to mark GATA-4 proteins. Figures $\mathbf{8 A}, \mathbf{B}$ shows that GATA-4 phosphorylation and nuclear translocation were markedly increased by 30 and $60 \mathrm{~min}$ of leptin treatment. Thus, leptin mediates vascular remodeling, at least in part, by a GATA-4-dependent mechanism.

\section{GATA-4 Nuclear Translocation is Dependent on the RhoA/ROCK Pathway and an Intact Cytoskeleton}

To examine whether the RhoA/ROCK pathway is involved in mediating GATA-4 nuclear translocation in response to leptin, RASMC were pre-treated with Y-27632 $(10 \mu \mathrm{mol} / \mathrm{L})$ or cytochalasin $\mathrm{D}(1 \mu \mathrm{mol} / \mathrm{L})$ followed by leptin treatment for 60 min. GATA-4 nuclear translocation was noticeably abolished by treatment with either Y-27632 or cytochalasin D (Figure 9), indicating that the RhoA/ROCK pathway and an intact cytoskeleton are crucial for leptin-induced GATA-4 translocation to the nucleus.

\section{ROS Depletion Inhibits GATA-4 Nuclear Translocation}

To study whether there is an interaction between ROS and GATA4 , the Nox inhibitor apocynin $(1 \mu \mathrm{mol} / \mathrm{L})$ was added to RASMC to deplete ROS, followed by leptin treatment. RASMC treated with apocynin and leptin for $60 \mathrm{~min}$ exhibited a marked reduction in GATA-4 nuclear translocation compared to leptin-treated cells alone (Figure 10), indicating that ROS are upstream to GATA-4 translocation.

\section{DISCUSSION}

Understanding the molecular mechanisms involved in cardiovascular disease during obesity and hypertension is crucial in order to identify novel therapeutic targets for treating their associated-vascular and cardiac disorders. Obesity is associated with high levels of the circulating hormone leptin (hyperleptinemia), which in turn is responsible for several cardiovascular diseases. The exact mechanism(s) by which leptin is associated with hypertension and the progression of cardiovascular diseases remains to be investigated as discussed in this work.

The major findings in the present study include: (1) Identification of a direct effect of the mechanical stretch model (mimicking hypertension) on endogenous leptin synthesis in VSMCs. (2) Involvement of Nox1 and Nox4 but not Nox2 expression in mechanical stretch-induced ROS formation in VSMCs. (3) Leptin induces ROS formation in VSMCs, in a RhoA/ROCK-dependent manner. (4) Leptin induces GATA-4 phosphorylation and nuclear translocation through the RhoA/ROCK pathway and ROS, as summarized in Figure 11. 


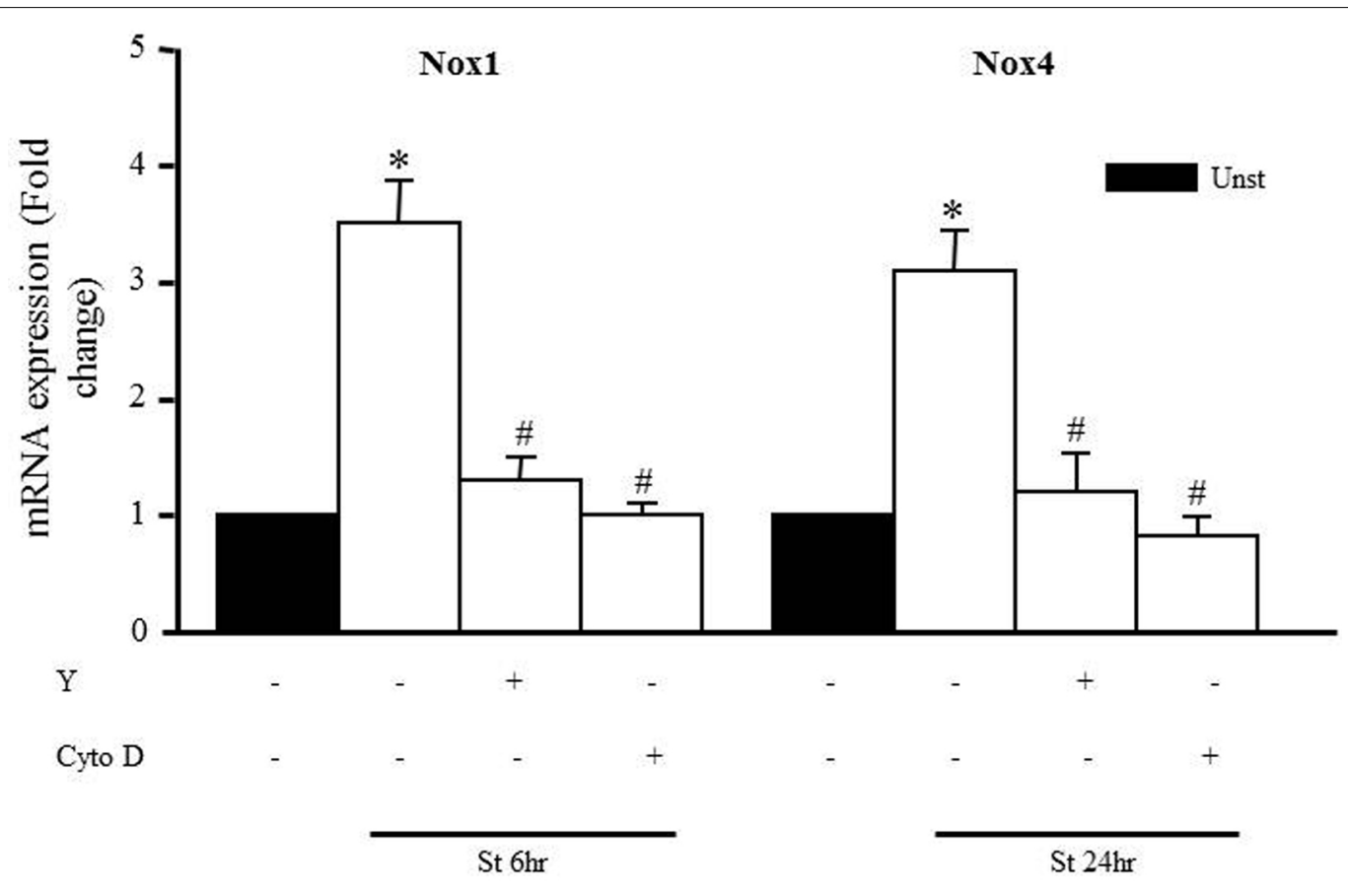

FIGURE 7 | Role of the RhoA/ROCK pathway and intact cytoskeleton on Nox expression. Effect of Y-27632 (Y; $10 \mu$ mol/L) or cytochalasin D (Cyto D; $1 \mu \mathrm{mol} / \mathrm{L})$ on mechanical stretch-induced Nox1 and Nox4 gene expression using qPCR analysis. $(n=8-10) .{ }^{*} p<0.05$ versus unstretched. $\# p<0.05$ versus stretched.

A

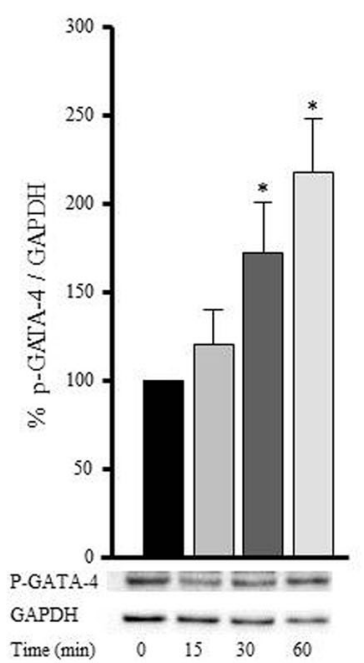

B

$$
\begin{aligned}
& \text { Lep } 15 \mathrm{~min} \\
& \text { Lep } 30 \mathrm{~min} \\
& \text { Lep } 60 \mathrm{~min}
\end{aligned}
$$

DAPI

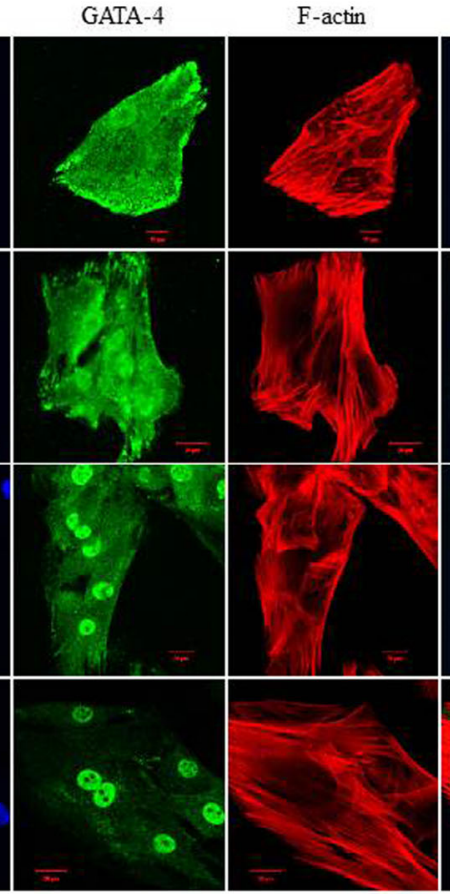

Merged

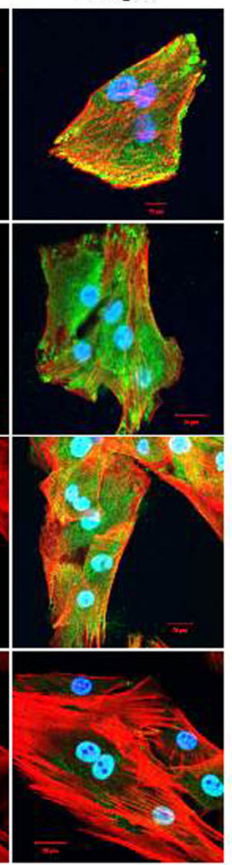

FIGURE 8 | Leptin-induced GATA-4 phosphorylation and nuclear translocation. RASMC were treated with leptin (3.1 nmol/L) for 15, 30 , and 60 min followed by Western blotting (A) or laser confocal microscopic analysis (B) for GATA-4 detection. Protein lysates were immunoblotted using anti-p-GATA-4 antibody to detect GATA-4 phosphorylation using Western blot (A). For immunostaining to detect GATA-4 translocation to the nucleus, GATA-4 antibody was visualized by CruzFluor 488-conjugated secondary antibody (second panel; green). Acti-stain 555 phalloidin stained F-actin (third panel; red), while DAPI stained the nuclei blue (first panel; blue). The overlay of DAPI, GATA-4, and F-actin (merged) is shown in the right panel. 


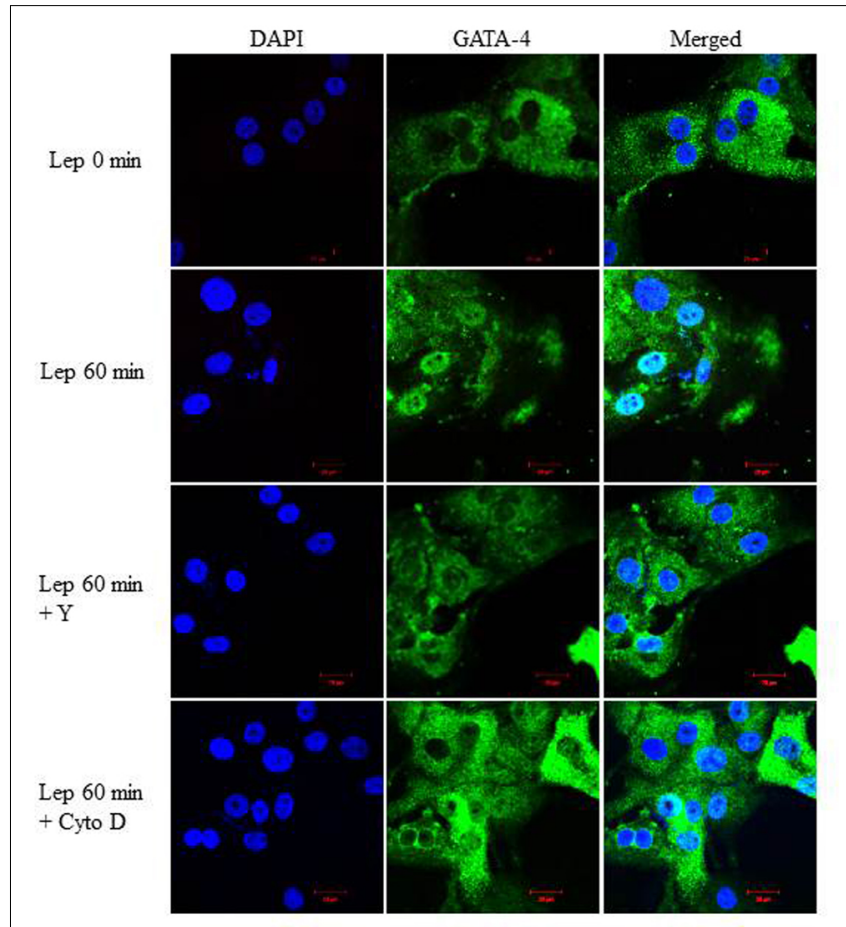

FIGURE 9 | Role of the RhoA/ROCK pathway in leptin-induced GATA-4 translocation. Representative confocal microscopic images of RASMC to study the effect of $\mathrm{Y}-27632$ (Y; $10 \mu \mathrm{mol} / \mathrm{L}$ ) or cytochalasin D (Cyto D; $1 \mu \mathrm{mol} / \mathrm{L})$ on leptin-induced GATA-4 translocation. DAPI stained the nuclei (left panel; blue) and GATA-4 was detected using CruzFluor 488-conjugated secondary antibody (middle panel; green). The overlay (merged) is shown in the right panel. GATA-4 translocation in response to leptin was abolished by $Y$ and Cyto D.

Rat portal vein organ culture was used in this study to evaluate the effect of mechanical stretch on vascular remodeling. This exvivo model was used since it has been well-characterized in a number of recent publications related to the hypertrophic effect of mechanical stretch (Zeidan et al., 2000, 2003a,b, 2004, 2005; Ren et al., 2010; Turczynska et al., 2012, 2013).

Because of its myogenic vasomotion, the RPV has been used in the development of vasoactive drugs as an analog of small pre-capillary resistance vessels (Ljung, 1990). Moreover, the longitudinally oriented musculature in the RPV makes it an ideal blood vessel for investigating the effect of mechanical stress on muscle hypertrophy by stretching it by weight loading rather than perfusion. In addition, mechanical stretch maintained the differentiated status of the VSMCs in this ex-vivo model as evidenced by a marked increase in SM22 synthesis (differentiation marker for VSMCs) and muscle contractility, unlike VSMCs in cell culture (Zeidan et al., 2003b). Moreover, the effect of increased RPV pressure (in vivo) due to partial occlusion in the portal vein has been implicated in VSMC hypertrophy (Malmqvist and Arner, 1988, 1990). Many signaling complexes act as sensors and transducers of mechanical stretch such as growth factors, ROS, nuclear factor kappaB, and $\mathrm{Na}^{+} / \mathrm{H}^{+}$exchanger isoform 1 (Dzau, 1993; Koller, 2002; Lemarie et al., 2006; Paravicini and Touyz, 2006; Haga et al., 2007). We have previously shown that mechanical stretch stimulated VSMC hypertrophy via the activation of MAPK pathways, RhoA/ROCK pathways, and actin cytoskeleton remodeling (Zeidan et al., 2000, 2003a,b, 2004, 2005).

Many studies have shown a clear relationship between plasma leptin levels and hypertension in different animal models (Hiraoka et al., 1997; reviewed, by Stenvinkel, 2000) and in humans (Agata et al., 1997; Uckaya et al., 1999). However, the mechanism by which hypertension increases plasma leptin levels is still not clear. Plasma levels of leptin, in general, are higher in essential hypertensive patients (not obese) compared to controls (Agata et al., 1997; Uckaya et al., 1999). Indeed, we have previously found that mechanical stretch enhances the release of leptin from VSMCs to culture media and increases leptin mRNA expression after 1,2, and 3 days of stretching along with vascular remodeling (Zeidan et al., 2005).

The current study sought to delineate the possible role of increased mechanical stretch (hypertension) on leptin protein synthesis in VSMCs and on early time points of leptin release $(1,3,6,18 \mathrm{~h})$. Interestingly, we have found that significant alterations in leptin protein expression occurred after only $1 \mathrm{~h}$ of mechanical stretch coupled with lower intracellular leptin levels $24 \mathrm{~h}$ post mechanical stretch. The hypothesis for this decrease in the intracellular leptin levels after $24 \mathrm{~h}$ is that leptin was secreted outside the VSMCs and that the biosynthesis of leptin itself was downregulated; the underlying mechanism needs to be further investigated. However, these data highlighted the critical role of leptin in mechanical stretch induced-VSMC hypertrophy as discussed in previous findings from our lab (Zeidan et al., 2003a).

To further validate the above findings, CM taken from stretched RPVs was shown to induce RPV hypertrophy while CM from unstretched RPVs had no effect on RPV hypertrophy, indicating the presence of hypertrophic related-protein(s) in CM as shown in Figure 2. Adding the anti-leptin antibody to $\mathrm{CM}$ taken from stretched RPVs inhibited the hypertrophic effect of CM, indicating the important role of secreted leptin in mediating CMinduced RPV hypertrophy.

As for the dynamics of actin cytoskeleton, our work shows that mechanical stretch increases actin polymerization as reflected by an increase in the F-actin to G-actin ratio by 5.6 fold, while leptin increases it by 1.5 fold (Figure 4). The reported results are in line with the idea that leptin decreases the levels of G-actin with respect to F-actin via the RhoA/ROCK/p-cofilin pathway.

Among the aims of this study was to investigate the role of ROS formation in mechanical stretch-induced VSMC remodeling. ROS has several implications on cardiovascular functions (Zafari et al., 1998; Touyz and Schiffrin, 1999), including vascular remodeling. In this study, ROS formation was upregulated $1 \mathrm{~h}$ post mechanical stretch. Of interest, treating RPVs with exogenous leptin exhibited similar results to mechanical stretch, while inhibiting leptin synthesis in turn inhibited mechanical stretch-induced ROS formation. These data indicate that ROS formation is induced through leptin synthesis as shown in Figure 6. Taken together, our data strongly suggest the important pathophysiological roles of hypertension and hyperleptinemia for increased ROS production in VSMCs. 


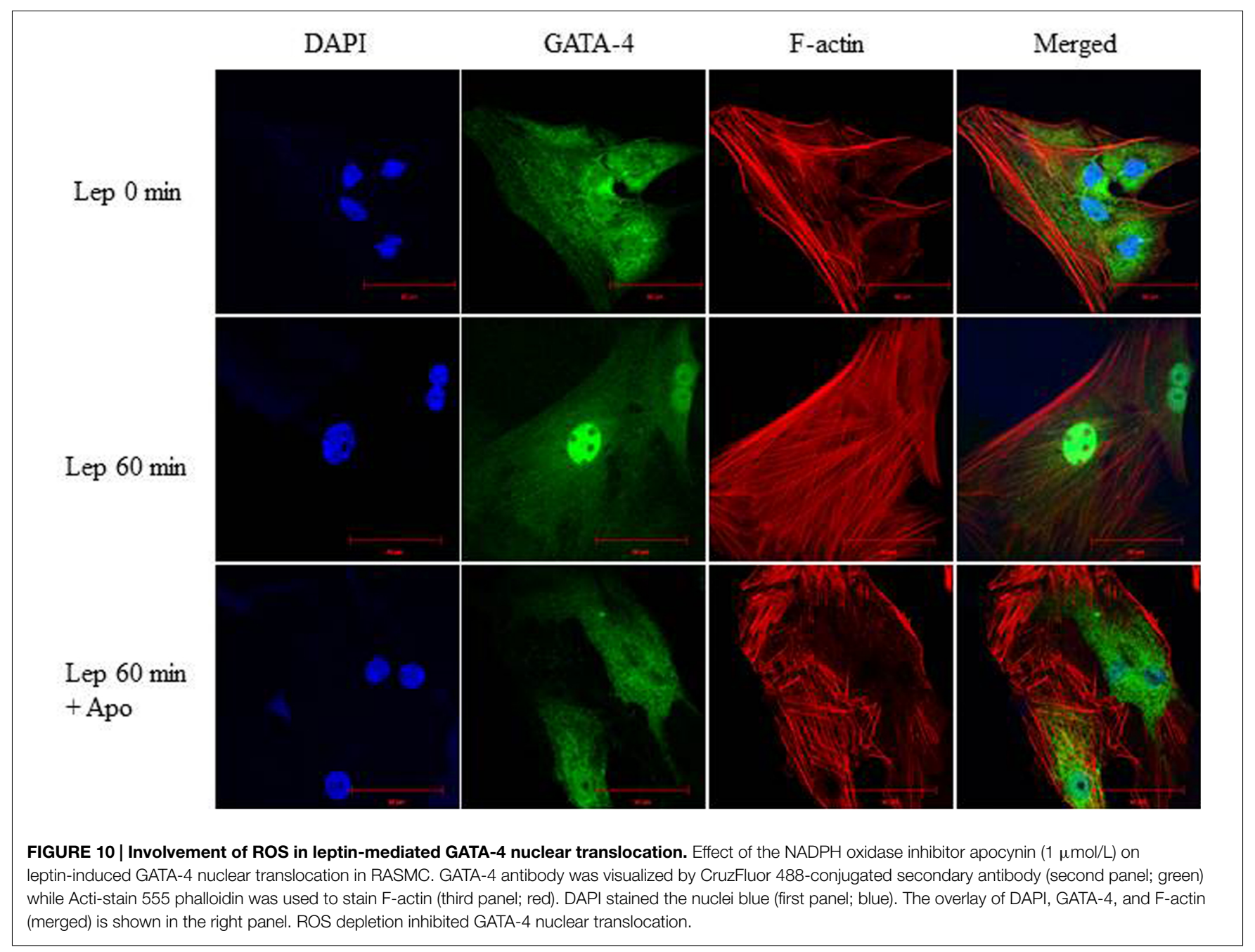

Moreover, this study shows a link between ROS production and the RhoA/ROCK pathway activation. ROCK inhibition and depolymerization of the actin cytoskeleton significantly lowered both leptin-/mechanical stretch-induced ROS formation, thereby placing ROS formation downstream to RhoA/ROCK (Figure 6).

Moreover, we analyzed the effect of mechanical stretch on the expression pattern of different NADPH oxidases (Nox1, Nox2, Nox4). Mechanical stretch upregulated Nox1 and Nox4 expressions but not Nox2, indicating the important role of Nox1 and Nox4 in mechanical stretch/hypertension-induced vascular remodeling. Nox1 expression increased significantly after $1 \mathrm{~h}$ of mechanical stretch and remained high throughout until $24 \mathrm{~h}$, indicating that Nox1 is perhaps an early response NADPH oxidase to stretch (Szöcs et al., 2002). Nox4 expression increased significantly after $18 \mathrm{~h}$ of stretch, suggesting that it is responsible for the late $(24 \mathrm{~h})$ production of ROS in response to stretch. Given these time points, we concluded that Nox1 and Nox4 are responsible for generating ROS in response to $24 \mathrm{~h}$ of stretch, but not at $1 \mathrm{~h}$ of stretch. Nox 2 expression did not change in response to stretch and thus not responsible for the increase in ROS formation after stretch. It is interesting to note that a recent study by Byrne et al. reported that Nox 2 expression and activation is not critical for pressure overload-induced cardiac hypertrophy (Byrne et al., 2003; Maytin et al., 2004). Moreover, the importance of Nox4 has been shown in pressure overload-induced left ventricular hypertrophy (Byrne et al., 2003). Our results have shown that Nox1 and Nox4 upregulation was attenuated by both ROCK inhibitor and actin depolarization agent, further suggesting an important role for the RhoA/ROCK pathway in downstream ROS formation.

Increased wall tension results in hypertrophy, which begins as a compensatory response, but is actually detrimental. The role of GATA-4 in promoting in hypertrophy has been well established in the cardiac system, since it is a transcription factor that activates hypertrophic gene expression like $\beta$-MHC, c-fos, c-jun, c-myc, BNP, and ANF (Chien et al., 1991; Liang and Gardner, 1999; Saadane et al., 1999; Babu et al., 2000). We already know that leptin induces VSMC hypertrophy (Zeidan et al., 2005), and this current study reveals a mechanism of leptin-induced VSMC hypertrophy (Figure 3). Furthermore, our present data indicate that leptin promotes the phosphorylation and nuclear translocation of GATA-4, and that this leptininduced GATA-4 activation is inhibited by the ROCK inhibitor and actin depolymerization agent (Y-27632 and cytochalasin D 


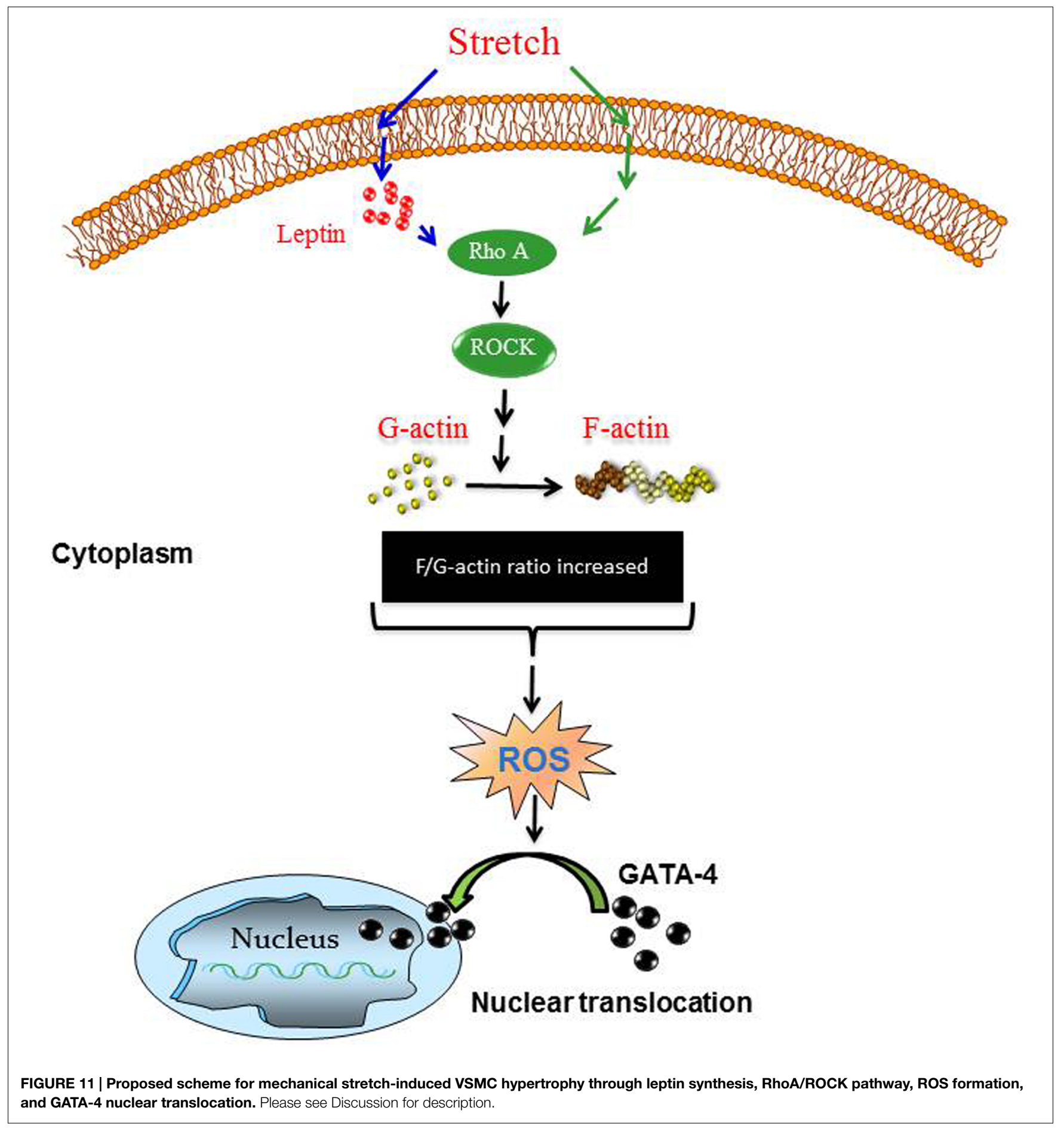

respectively). Since leptin and the RhoA/ROCK pathway are implicated in VSMC hypertrophy (Yamakawa et al., 2000; Zeidan et al., 2005), we believe that GATA- 4 activation and translocation plays a hypertrophic role in the vascular system as shown by these new findings. Moreover, the role of GATA- 4 has been linked in the vascular system by regulating cardiac angiogenesis (Heineke et al., 2007) and embryonic angiogenesis in the vascular plexus (Torregroza et al., 2012). The contribution of ROS to GATA-4 activation in response to leptin has been studied. The NAPDH oxidase inhibitor apocynin was used to inhibit ROS formation (Pi et al., 2013; Schroeter et al., 2013), followed by analysis of GATA-4 nuclear translocation. ROS depletion markedly abolished GATA-4 nuclear translocation in response to leptin. Therefore, these data indicate that ROS may activate GATA-4 and induce GATA-4 nuclear translocation.

In conclusion, this study highlighted the molecular mechanisms involved in mechanical stretch-induced VSMC hypertrophy and the critical involvement of endogenous leptin, 
ROS formation, and GATA-4 nuclear translocation. Based on our findings in this study, we were able to construct a putative pathway of the mechanism mediating the above changes of mechanical stretch/leptin cross-talk as depicted in Figure 11. As shown, mechanical stretch acts as an upstream regulator of ROS formation and GATA-4 nuclear translocation through leptin synthesis, RhoA/ROCK activation, and F/G-actin ratio changes (please refer to Figures 1, 3, 4, and 6)

Further research should be done in order to provide a more detailed picture of the mechanisms of action. The

\section{REFERENCES}

Agata, J., Masuda, A., Takada, M., Higashiura, K., Murakami, H., Miyazaki, Y., et al. (1997). High plasma immunoreactive leptin level in essential hypertension. Am. J. Hypertens. 10, 1171-1174. doi: 10.1016/S0895-7061(97) 00310-5

Babu, G. J., Lalli, M. J., Sussman, M. A., Sadoshima, J., and Periasamy, M. (2000). Phosphorylation of elk-1 by MEK/ERK pathway is necessary for c-fos gene activation during cardiac myocyte hypertrophy. J. Mol. Cell Cardiol. 32, 1447-1457. doi: 10.1006/jmcc.2000.1185

Byrne, J. A., Grieve, D. J., Bendall, J. K., Li, J. M., Gove, C., Lambeth, J. D., et al. (2003). Contrasting roles of NADPH oxidase isoforms in pressure-overload versus angiotensin II-induced cardiac hypertrophy. Circ. Res. 93, 802-805. doi: 10.1161/01.RES.0000099504.30207.F5

Chien, K. R., Knowlton, K. U., Zhu, H., and Chien, S. (1991). Regulation of cardiac gene expression during myocardial growth and hypertrophy: molecular studies of an adaptive physiologic response. FASEB J. 5, 3037-3046.

Clempus, R. E., and Griendling, K. K. (2006). Reactive oxygen species signaling in vascular smooth muscle cells. Cardiovasc. Res. 71, 216-225. doi: 10.1016/j.cardiores.2006.02.033

Dzau, V. J. (1993). The role of mechanical and humoral factors in growth regulation of vascular smooth muscle and cardiac myocytes. Curr. Opin. Nephrol. Hypertens. 2, 27-32. doi: 10.1097/00041552-199301000-00004

Fan, Z., Li, C., Qin, C., Xie, L., Wang, X., Gao, Z., et al. (2014). Role of the PI3K/AKT pathway in modulating cytoskeleton rearrangements and phenotype switching in rat pulmonary arterial vascular smooth muscle cells. DNA Cell Biol. 33.1, 12-19. doi: 10.1089/dna.2013.2022

Ghantous, C. M., Azrak, Z., Hanache, S., Abou-Kheir, W., and Zeidan, A. (2015). Differential role of leptin and adiponectin in cardiovascular system. Int. J. Endocrinol. 2015, 534320. doi: 10.1155/2015/534320

Haga, J. H., Li, Y. S., and Chien, S. (2007). Molecular basis of the effects of mechanical stretch on vascular smooth muscle cells. J. Biomech. 40, 947-960. doi: 10.1016/j.jbiomech.2006.04.011

Heineke, J., Auger-Messier, M., Xu, J., Oka, T., Sargent, M. A., York, A., et al. (2007). Cardiomyocyte GATA4 functions as a stress-responsive regulator of angiogenesis in the murine heart. J. Clin. Invest. 117, 3198-3210. doi: $10.1172 / \mathrm{JCI} 32573$

Herzig, T. C., Jobe, S. M., Aoki, H., Molkentin, J. D., Cowley, A. W. Jr., Izumo, S., et al. (1997). Angiotensin II typela receptor gene expression in the heart: AP-1 and GATA-4 participate in the response to pressure overload. Proc. Natl. Acad. Sci. U.S.A. 94, 7543-7548. doi: 10.1073/pnas.94.14.7543

Hiraoka, J., Hosoda, K., Ogawa, Y., Ikeda, K., Nara, Y., Masuzaki, H., et al. (1997). Augmentation of obese (ob) gene expression and leptin secretion in obese spontaneously hypertensive rats (obese SHR or Koletsky rats). Biochem. Biophys. Res. Commun. 231, 582-585. doi: 10.1006/bbrc.1997.6145

Hsieh, Y. L., Tsai, Y. L., Shibu, M. A., Su, C. C., Chung, L. C., Pai, P., et al. (2015). ZAK induces cardiomyocyte hypertrophy and brain natriuretic peptide expression via $\mathrm{p} 38 / \mathrm{JNK}$ signaling and GATA4/c-Jun transcriptional factor activation. Mol. Cell. Biochem. 405, 1-9. doi: 10.1007/s11010-015-2389-z

Kai, H., Kudo, H., Takayama, N., Yasuoka, S., Kajimoto, H., and Imaizumi, T. (2009). Large blood pressure variability and hypertensive cardiac remodeling-role of cardiac inflammation. Circ. J. 73, 2198-2203. doi: 10.1253/circj.CJ-09-0741

Koller, A. (2002). Signaling pathways of mechanotransduction in arteriolar endothelium and smooth muscle cells in hypertension. Microcirculation 9, 277-294. doi: 10.1038/sj.mn.7800142 links between the different signal transducers may provide a helpful approach in developing potential therapeutic strategies to attenuate the harmful effects of hypertension and leptin on vascular remodeling.

\section{ACKNOWLEDGMENTS}

This work was supported by Medical Practice Plan (MPP), Faculty of Medicine at AUB, and the National Council for Scientific Research (CNRS) in Lebanon to AZ.

Lemarie, C. A., Tharaux, P. L., Esposito, B., Tedgui, A., and Lehoux, S. (2006). Transforming growth factor-alpha mediates nuclear factor kappaB activation in strained arteries. Circ. Res. 99, 434-441. doi: 10.1161/01.RES.0000237388.89261.47

Liang, F., and Gardner, D. G. (1999). Mechanical strain activates BNP gene transcription through a p38/NF-кB-dependent mechanism. J. Clin. Invest. 104, 1603. doi: 10.1172/JCI7362

Li, H., Ung, C. Y., Ma, X. H., Li, B. W., Low, B. C., Cao, Z. W., et al. (2009). Simulation of crosstalk between small GTPase RhoA and EGFRERK signaling pathway via MEKK1. Bioinformatics 25.3, 358-364. doi: 10.1093/bioinformatics/btn635

Ljung, B. (1990). Vascular selectivity of felodipine: experimental pharmacology. J Cardiovasc. Pharmacol. 15, S11-S16. doi: 10.1097/00005344-19901500400003

Lord, G. M., Matarese, G., Howard, J. K., Baker, R. J., Bloom, S. R., and Lechler, R. I. (1998). Leptin modulates the T-cell immune response and reverses starvationinduced immunosuppression. Nature 394, 897-901. doi: 10.1038/29795

Lord, G. M., Matarese, G., Howard, J. K., Bloom, S. R., and Lechler, R. I. (2002). Leptin inhibits the anti-CD3-driven proliferation of peripheral blood $\mathrm{T}$ cells but enhances the production of proinflammatory cytokines. J. Leukoc. Biol. 72, $330-338$.

Lyle, A. N., and Griendling, K. K. (2006). Modulation of vascular smooth muscle signaling by reactive oxygen species. Physiology (Bethesda) 21, 269-280. doi: 10.1152/physiol.00004.2006

Maffei, M., Halaas, J., Ravussin, E., Pratley, R. E., Lee, G. H., Zhang, Y., et al. (1995). Leptin levels in human and rodent: measurement of plasma leptin and ob RNA in obese and weight-reduced subjects. Nat. Med. 1, 1155-1161. doi: 10.1038/nm1195-1155

Malmqvist, U., and Arner, A. (1988). Contractile properties during development of hypertrophy of the smooth muscle in the rat portal vein. Acta Physiol. Scand. 133, 49-61. doi: 10.1111/j.1748-1716.1988.tb08380.x

Malmqvist, U., and Arner, A. (1990). Isoform distribution and tissue contents of contractile and cytoskeletal proteins in hypertrophied smooth muscle from rat portal vein. Circ. Res. 66, 832-845. doi: 10.1161/01.RES.66.3.832

Margetic, S., Gazzola, C., Pegg, G. G., and Hill, R. A. (2002). Leptin: a review of its peripheral actions and interactions. Int. J. Obes. Relat. Metab. Disord. 26, 1407-1433. doi: $10.1038 /$ sj.ijo.0802142

Markowska, A., Belloni, A. S., Rucinski, M., Parenti, A. R., Nardelli, G. B., Drews, K., et al. (2005). Leptin and leptin receptor expression in the myometrium and uterine myomas: is leptin involved in tumor development? Int. J. Oncol. 27, 1505-1509.

Martin-Romero, C., Santos-Alvarez, J., Goberna, R., and Sanchez-Margalet, V. (2000). Human leptin enhances activation and proliferation of human circulating $\mathrm{T}$ lymphocytes. Cell Immunol 199, 15-24. doi: 10.1006/cimm.1999.1594

Matsui, H., Motooka, M., Koike, H., Inoue, M., Iwasaki, T., Suzuki, T., et al. (2007). Ischemia/reperfusion in rat heart induces leptin and leptin receptor gene expression. Life Sci. 80, 672-680. doi: 10.1016/j.lfs.2006.10.027

Maytin, M., Siwik, D. A., Ito, M., Xiao, L., Sawyer, D. B., Liao, R., et al. (2004). Pressure overload-induced myocardial hypertrophy in mice does not require gp91phox. Circulation 109, 1168-1171. doi: 10.1161/01.CIR.0000117229.60628.2F

Mei, Y., Thompson, M. D., Cohen, R. A., and Tong, X. (2015). Autophagy and oxidative stress in cardiovascular diseases. Biochim. Biophys. Acta 1852, 243-251. doi: 10.1016/j.bbadis.2014.05.005 
Molkentin, J. D., Lu, J. R., Antos, C. L., Markham, B., Richardson, J., Robbins, J., et al. (1998). A calcineurin-dependent transcriptional pathway for cardiac hypertrophy. Cell 93.2, 215-228. doi: 10.1016/S0092-8674(00)81573-1

Montezano, A. C., and Touyz, R. M. (2012). Molecular mechanisms of hypertension-reactive oxygen species and antioxidants: a basic science update for the clinician. Can J. Cardiol. 28, 288-295. doi: 10.1016/j.cjca.2012. 01.017

Mutze, J., Roth, J., Gerstberger, R., Matsumura, K., and Hubschle, T. (2006). Immunohistochemical evidence of functional leptin receptor expression in neuronal and endothelial cells of the rat brain. Neurosci. Lett. 394, 105-110. doi: 10.1016/j.neulet.2005.10.031

Nelson, T. J., Balza, R. Jr., Xiao, Q., and Misra, R. P. (2005). SRF-dependent gene expression in isolated cardiomyocytes: regulation of genes involved in cardiac hypertrophy. J. Mol. Cell Cardiol. 39, 479-489. doi: 10.1016/j.yjmcc.2005. 05.004

Oka, T., Maillet, M., Watt, A. J., Schwartz, R. J., Aronow, B. J., Duncan, S. A., et al. (2006). Cardiac-specific deletion of Gata4 reveals its requirement for hypertrophy, compensation, and myocyte viability. Circ. Res. 98.6, 837-845. doi: 10.1161/01.RES.0000215985.18538.c4

Paravicini, T. M., and Touyz, R. M. (2006). Redox signaling in hypertension. Cardiovasc. Res. 71, 247-258. doi: 10.1016/j.cardiores.2006.05.001

Paravicini, T. M., and Touyz, R. M. (2008). NADPH oxidases, reactive oxygen species, and hypertension: clinical implications and therapeutic possibilities. Diabetes Care 31(Suppl. 2), S170-S180. doi: 10.2337/dc08-s247

Pi, Y., Zhang, L. L., Li, B. H., Guo, L., Cao, X. J., Gao, C. Y., et al. (2013). Inhibition of reactive oxygen species generation attenuates TLR4-mediated proinflammatory and proliferative phenotype of vascular smooth muscle cells. Lab. Invest. 93, 880-887. doi: 10.1038/labinvest.2013.79

Rahmouni, K., and Haynes, W. G. (2004). Leptin and the cardiovascular system. Recent Prog. Horm. Res. 59, 225-244. doi: 10.1210/rp.59.1.225

Rajapurohitam, V., Gan, X. T., Kirshenbaum, L. A., and Karmazyn, M. (2003). The obesity-associated peptide leptin induces hypertrophy in neonatal rat ventricular myocytes. Circ. Res. 93, 277-279. doi: 10.1161/01.RES.0000089255.37804.72

Ren, J., Albinsson, S., and Hellstrand, P. (2010). Distinct effects of voltageand store-dependent calcium influx on stretch-induced differentiation and growth in vascular smooth muscle. J. Biol. Chem. 285, 31829-31839. doi: 10.1074/jbc.M109.097576

Saadane, N., Alpert, L., and Chalifour, L. E. (1999). Expression of immediate early genes, GATA-4, and Nkx-2.5 in adrenergic-induced cardiac hypertrophy, and during regression in adult mice. Br. J. Pharmacol. 127, 1165-1176. doi: 10.1038/sj.bjp.0702676

Schroeter, M. R., Leifheit-Nestler, M., Hubert, A., Schumann, B., Gluckermann, R., Eschholz, N., et al. (2013). Leptin promotes neointima formation and smooth muscle cell proliferation via NADPH oxidase activation and signalling in caveolin-rich microdomains. Cardiovasc. Res. 99, 555-565. doi: $10.1093 / \mathrm{cvr} / \mathrm{cvt} 126$

Sinha, M. K., Opentanova, I., Ohannesian, J. P., Kolaczynski, J. W., Heiman, M. L., Hale, J., et al. (1996). Evidence of free and bound leptin in human circulation. Studies in lean and obese subjects and during short-term fasting. J. Clin. Invest. 98, 1277-1282. doi: 10.1172/JCI118913

Stenvinkel, P. (2000). Leptin and blood pressure-is there a link? Nephrol. Dial Trans. 15, 1115-1117. doi: 10.1093/ndt/15.8.1115

Sutter, M. C. (1990). The mesenteric-portal vein in research. Pharmacol. Rev. 42, 287-325.

Szöcs, K., Lassègue, B., Sorescu, D., Hilenski, L. L., Valppu, L., Couse, T. L., et al. (2002). Upregulation of Nox-based NAD (P) $\mathrm{H}$ oxidases in restenosis after carotid injury. Arterioscler. Thromb. Vasc. Biol. 22, 21-27. doi: 10.1161/hq0102.102189

Torregroza, I., Holtzinger, A., Mendelson, K., Liu, T. C., Hla, T., and Evans, T. (2012). Regulation of a vascular plexus by gata 4 is mediated in zebrafish through the chemokine sdf1a. PLoS ONE 7:e46844. doi: 10.1371/journal.pone.0046844

Touyz, R. M., and Schiffrin, E. L. (1999). Ang II-stimulated superoxide production is mediated via phospholipase D in human vascular smooth muscle cells. Hypertension 34, 976-982. doi: 10.1161/01.HYP.34.4.976

Touyz, R. M., and Schiffrin, E. L. (2004). Reactive oxygen species in vascular biology: implications in hypertension. Histochem. Cell Biol. 122, 339-352. doi: 10.1007/s00418-004-0696-7
Turczynska, K. M., Bhattachariya, A., Sall, J., Goransson, O., Sward, K., Hellstrand, P., et al. (2013). Stretch-sensitive down-regulation of the miR-144/451 cluster in vascular smooth muscle and its role in AMP-activated protein kinase signaling. PLOS ONE 8:e65135. doi: 10.1371/journal.pone.0065135

Turczynska, K. M., Sadegh, M. K., Hellstrand, P., Sward, K., and Albinsson, S. (2012). MicroRNAs are essential for stretch-induced vascular smooth muscle contractile differentiation via microRNA (miR)-145-dependent expression of L-type calcium channels. J. Biol. Chem. 287, 19199-19206. doi: 10.1074/jbc.M112.341073

Uckaya, G., Ozata, M., Sonmez, A., Kinalp, C., Eyileten, T., Bingol, N., et al. (1999). Plasma leptin levels strongly correlate with plasma renin activity in patients with essential hypertension. Horm. Metab. Res. 31, 435-438. doi: 10.1055/s-2007978769

Yamakawa, T., Tanaka, S., Numaguchi, K., Yamakawa, Y., Motley, E. D., Ichihara, S., et al. (2000). Involvement of Rho-kinase in angiotensin II-induced hypertrophy of rat vascular smooth muscle cells. Hypertension 35, 313-318. doi: 10.1161/01.HYP.35.1.313

Zafari, A. M., Ushio-Fukai, M., Akers, M., Yin, Q., Shah, A., Harrison, D. G., et al. (1998). Role of NADH/NADPH oxidase-derived $\mathrm{H} 2 \mathrm{O} 2$ in angiotensin II-induced vascular hypertrophy. Hypertension 32, 488-495. doi: 10.1161/01.HYP.32.3.488

Zeidan, A., Broman, J., Hellstrand, P., and Sward, K. (2003a). Cholesterol dependence of vascular ERK1/2 activation and growth in response to stretch: role of endothelin-1. Arterioscler. Thromb. Vasc. Biol. 23, 1528-1534. doi: 10.1161/01.ATV.0000090129.75275.C2

Zeidan, A., Nordstrom, I., Albinsson, S., Malmqvist, U., Sward, K., and Hellstrand, P. (2003b). Stretch-induced contractile differentiation of vascular smooth muscle: sensitivity to actin polymerization inhibitors. Am. J. Physiol. Cell Physiol. 284, C1387-C1396. doi: 10.1152/ajpcell.00508.2002

Zeidan, A., Javadov, S., and Karmazyn, M. (2006). Essential role of Rho/ROCKdependent processes and actin dynamics in mediating leptin-induced hypertrophy in rat neonatal ventricular myocytes. Cardiovasc. Res. 72, 101-111. doi: 10.1016/j.cardiores.2006.06.024

Zeidan, A., and Karmazyn, M. (2006). Leptin and vascular smooth muscle. Curr. Vasc. Pharmacol. 4, 383-393. doi: 10.2174/157016106778521634

Zeidan, A., Nordstrom, I., Dreja, K., Malmqvist, U., and Hellstrand, P. (2000). Stretch-dependent modulation of contractility and growth in smooth muscle of rat portal vein. Circ. Res. 87, 228-234. doi: 10.1161/01.RES.87.3.228

Zeidan, A., Paylor, B., Steinhoff, K. J., Javadov, S., Rajapurohitam, V., Chakrabarti, S., et al. (2007). Actin cytoskeleton dynamics promotes leptin-induced vascular smooth muscle hypertrophy via RhoA/ROCK- and phosphatidylinositol 3kinase/protein kinase B-dependent pathways. J. Pharmacol. Exp. Ther. 322, 1110-1116. doi: 10.1124/jpet.107.122440

Zeidan, A., Purdham, D. M., Rajapurohitam, V., Javadov, S., Chakrabarti, S., and Karmazyn, M. (2005). Leptin induces vascular smooth muscle cell hypertrophy through angiotensin II- and endothelin-1-dependent mechanisms and mediates stretch-induced hypertrophy. J. Pharmacol. Exp. Ther. 315, 1075-1084. doi: 10.1124/jpet.105.091561

Zeidan, A., Sward, K., Nordstrom, I., Ekblad, E., Zhang, J. C., Parmacek, M. S., et al. (2004). Ablation of SM22alpha decreases contractility and actin contents of mouse vascular smooth muscle. FEBS Lett. 562, 141-146. doi: 10.1016/S00145793(04)00220-0

Zhang, Y., Griendling, K. K., Dikalova, A., Owens, G. K., and Taylor, W. R. (2005). Vascular hypertrophy in angiotensin II-induced hypertension is mediated by vascular smooth muscle cell-derived $\mathrm{H} 2 \mathrm{O} 2$. Hypertension 46, 732-737. doi: 10.1161/01.HYP.0000182660.74266.6d

Conflict of Interest Statement: The authors declare that the research was conducted in the absence of any commercial or financial relationships that could be construed as a potential conflict of interest.

Copyright (c) 2015 Ghantous, Kobeissy, Soudani, Rahman, Al-Hariri, Itani, Sabra and Zeidan. This is an open-access article distributed under the terms of the Creative Commons Attribution License (CC BY). The use, distribution or reproduction in other forums is permitted, provided the original author(s) or licensor are credited and that the original publication in this journal is cited, in accordance with accepted academic practice. No use, distribution or reproduction is permitted which does not comply with these terms. 